\title{
The (de)composition of event predicates
}

\author{
Boban Arsenijević, Berit Gehrke, Rafael Marín
}

\begin{abstract}
This chapter offers an overview of the advancements made in the semantic theory of events and introduces its central notions and current issues to serve as background information relevant for the contributions included in the volume. It is structured around two main axes: compositional and decompositional approaches to the semantics of event predicates. We argue that, while composition and decomposition are at times treated as two competing ways to deal with the semantics of event predicates, they can actually be seen as two sides of the same coin, as essential parts of the subatomic semantics of event predicates. Along with these two axes, we address how adverbial modification served as modification for event semantics as well as its use as diagnostics for the structural complexity or for particular properties of eventualities, such as (a)telicity or scalarity.
\end{abstract}

\section{Subatomic semantics of event predicates}

The aspectual classification established by Vendler (1957) half a century ago is still valid today and constitutes the basic ontological inventory of event predicates in current aspectual theory. The way we conceive of the internal configuration of such predicates, however, has changed more profoundly. On the one hand, increasingly greater richness of detail has been added to the logical representations for event predicates, from Davidson's (1967) use of event arguments and so-called Neo-Davidsonian approaches (e.g. Higginbotham 1985, Parsons 1990), to representations which focus on the relation between eventualities and their parts and to the decomposition of event predicates, often referred to in terms of 'event structure' (e.g. Pustejovsky 1995). On the other hand, the models for event semantics have been enriched, for example, by 
imposing a mereological structure (e.g. Krifka 1989, Lasersohn 1990), hence focusing on compositional aspects of event predicates.

Mereological approaches are closely related to so-called aspectual composition, which investigates the contribution of the verb and other argument(s) to the aspectual value of predicates. For example, to determine whether a predicate is telic or not, not only the verb has to be taken into account, but also (at least) the internal argument, particularly its quantificational properties (Verkuyl 1972). More recently, definitions of telicity based on the notion of a scale have been advanced (starting with Hay et al. 1999), according to which it is not necessarily the quantificational properties of the internal argument that determine the telicity of a predicate but rather a scale, a linearly ordered set of points, that can be associated with the verb, the internal argument or other elements in the clause. Thus, when dealing with aspectual composition we have to decide which is the most suitable level of aspectual analysis: the verb, the VP or the whole sentence; and this leads us directly to argument structure and thematic roles (Krifka 1989, Tenny 1994).

While decomposition and composition are at times treated as two competing ways to deal with the semantics of event predicates, we believe they can actually be seen as two sides of the same coin, as essential parts of the subatomic semantics of event predicates (to borrow Parsons' 1990 term). Along with decompositional and mereological approaches, the two main axes that articulate this volume, there is an additional ingredient concerning the subatomic semantics of event predicates: adverbial modification. An important argument in favor of introducing eventualities into the ontology came from the possibility to treat certain adverbial modifiers intersectively, as modifying an eventuality. Furthermore, there are adverbs which serve as diagnostics for the structural complexity or for particular properties of eventualities, such as (a)telicity or scalarity.

In traditional grammar, the meanings of different aspectual forms have typically been accounted for in terms of temporal relations. Aspect $^{1}$ was taken as a specification of the viewpoint on the situation

\footnotetext{
${ }^{1}$ It is common to distinguish between two different notions of aspect, grammatical aspect (viewpoint aspect, e.g. (im)perfective or aspectual meanings associated with progressive and perfect tenses) vs. lexical (predicational) aspect (also Aktionsart), associated with (a)telicity.
} 
described by verbal predicates (predicates expressed by the VP). Formal semantic accounts grew from this approach, and more or less explicitly took events as temporal intervals of such predicates. A milestone in this type of approaches was Reichenbach (1947), who proposed a system of three types of temporal intervals, event time, reference time and speech time, whose mutual relations were specified by different grammatical aspects and tenses, with restrictions parametrically varying across languages. In a similar vein we find early treatments of the semantics of verbal predicates, such as the work of Bennett and Partee (1972) or Verkuyl (1972). Their approach to the semantics of events, where 'event' is merely a descriptive notion, without implications for the domain of semantic types and ontology, is still represented in the work of semanticists who deny that the introduction of events as a type is beneficiary for the semantics in the respective domain, such as Verkuyl (2000).

The Davidsonian turn, i.e. the introduction of event arguments and of events as a separate type in the ontology of semantic objects, brought about a different approach to the subject. Events are now treated as objects, which are described by event predicates and referred to by expressions with a deictic capacity and which include descriptions, similar to nominal reference. Properties of events are properties included in event predicates - predicates applying to event arguments and enabling their reference to objects of the type of events. While most of the current volume takes the perspective of event semantics, some papers are either independent of this division or even written in a temporal semantics perspective.

This introduction, which aims at outlining the state of the art of current semantic theory of events and providing a general background for the main issues addressed in the volume, is structured as follows. In section 2, we discuss issues related to aspectual composition, such as the contribution of the verb itself, its arguments, as well as the notion of scale. In section 3, we turn to adverbial modification, which has been used as a main argument for introducing the event argument, as well as diagnostics for the structural complexity or particular properties of event predicates or

While the notion of aspect here deals with viewpoint aspect, in the remainder of this introduction we will mainly be concerned with lexical aspect. 
their underlying scale. Section 4 addresses psycholinguistic investigations into event predicates. Finally, section 5 concludes.

\section{Aspectual Composition}

Vendler (1957) based his four-way distinction between states, activities, accomplishments, and achievements, on two main criteria, the (in)compatibility with particular temporal adverbials and the (in)compatibility with the Progressive in English. First, accomplishments and achievements pattern together in that they are incompatible with for-adverbials (aka durative adverbials), but compatible with in-adverbials (aka frame adverbials) ((1)).

(1) a. I ran a mile *for/in an hour.

b. You reached the summit * for/in an hour.

Vendler notes that accomplishments and achievements are not homogeneous, since they have a 'set terminal point'. This property is commonly associated with telicity. States and activities, on the other hand, behave like atelic predicates, since they are compatible with for-adverbials, but not with in-adverbials ((2)).

(2) a. He stood in the corner for/*in an hour.

b. She ran for/*in an hour.

The second diagnostics groups states and achievements together, which are unacceptable in the progressive ((3a)), whereas activities and accomplishments are good inputs for the progressive ((3b)).

(3) a. *She was seeing a spider.

* He was finding a key.

b. You were running.

I was building a house.

This fact is often derived from the intuition that the progressive needs to apply to predicates that are dynamic and durative, allowing extension in time. States are not dynamic, however, and 
achievements are thought of as taking place at instants and thus not allowing for duration. ${ }^{2}$

Most of the literature on eventualities takes Vendler's division as a starting point, although it has been modified in several directions. For instance, Bach $(1981,1986)$ or Verkuyl (1993) make a threeway-distinction between states, processes (Vendler's activities ACT), and events (Vendler's accomplishments and achievements). Discourse theories such as Kamp and Reyle (1993) or ter Meulen (1995) usually distinguish between events and states (at the discourse level), and it is less clear where to locate processes / activities in such approaches (but see de Swart 1998). Others have added more classes, such as semelfactives (see, e.g., Comrie 1976, Smith 1991, Rothstein 2004), or degree achievements (in the sense of Dowty 1979; see, e.g., Hay et al. 1999). Much debate is found on the class of states, sometimes leading to a two-way division under different labels, e.g. static vs. dynamic states (Bach 1981, 1986, see also Dowty 1979, Maienborn 2005), or to denying that states belong to the classes of events altogether, for example in not (at least not all) being associated with an event argument (e.g. Katz 2003, 2008, Maienborn 2005). ${ }^{3}$

Martin (this volume) adds to the discussion about states. Given that the availability of manner modification has been treated as a hallmark of event predicates, she tries to give a finer analysis of particular types of manner modifiers that do or do not apply to states. She shows that in most cases the relevant facts are not related to the stative nature of the predicate, but to other independent properties. We will come back to the details of her proposal in section 3, when we discuss adverbial modification. Fleischhauer (this volume), and to some extent also Mittwoch (this volume), tackle the issue of whether degree achievements are a separate class, and what their distinctive properties are.

\footnotetext{
${ }^{2}$ Since Vendler, more tests have been proposed to distinguish between different classes of event predicates and in particular to distinguish telic from atelic predicates, such as the compatibility with certain degree modifiers, the potential for ambiguity with modifiers like almost, again, among others. Many of the diagnostics taken in isolation, including the two tests mentioned here, are problematic. In section 2.4, we will come back to this issue.

${ }^{3}$ See also Kratzer (1995), who proposes that only stage level but not individual level predicates, in the sense of Carlson (1977), contain an event argument in their argument structure.
} 
Vendler's classification, though probably not intended as such, has often been criticized as classifying verbs without taking into account the role of the argument(s) or other elements in the sentence. The received view nowadays is that to determine which class a predicate belongs to or whether it is telic, at least the semantic properties of the internal argument of the verb has to be taken into account as well, making the VP the relevant level to look at. Others have argued that the notion of telicity, a semantic property of predicates of different degrees of complexity, should be dissociated from the structural properties associated with different classes of event predicates (e.g. Rothstein 2004).

The literature on eventualities has been divided with respect to the relevant property that determines whether an eventuality is telic or not. The decompositional camp takes this to be the endpoint (aka culmination, termination, telos, result, phase transition): a discrete stage (state) that the situation needs to reach in order to be truthfully described by the respective predicate (Parsons 1990, Pustejovsky 1991, 1995, and many others). Eventualities with an endpoint (those that describe a definite change of state, in the sense of Dowty 1979) are telic, those without it (that do not describe a definite change of state) are atelic. The quantity camp, on the other hand, considers properties of quantity as a necessary and sufficient semantic property in the definition of aspect (Bennett and Partee 1972, Verkuyl 1972, Krifka 1989, among others). Eventualities can or cannot have the subinterval property, they can have an unbounded or bounded quantity, or more generally they can be homogeneous or quantized, and this corresponds to the two major aspectual classes: the atelic and telic eventualities. ${ }^{4}$

In sections 2.1 to 2.4 we will sketch this development and different approaches to telicity. We will address elements that have been argued to contribute to the aspectual interpretation of a sentence, such as the verb, its argument(s), and some more abstract, explicit or implicit element like a scale. In section 2.5 we will return to the diagnostics that have been proposed to distinguish between telic and atelic predicates and address some of the problems they face.

\footnotetext{
${ }^{4}$ An event predicate has the subinterval property if when it holds of a temporal interval, then it also holds of all the parts of this interval (perhaps to the exclusion of those reaching the atomic level of the event predicate in question). Predicates with the subinterval property are atelic.
} 


\subsection{Event-argument homomorphism}

Verkuyl (1972, and subsequent work) was probably the first to systematically deal with the contribution of the verb's argument(s) to the overall aspectual interpretation of a given sentence. In his theory, a predicate is telic (terminative under his terminology) if the verb is dynamic (or additive, as specified by a +ADDTO feature) and if its relevant argument is specified for quantity (+SQA) ((4a), as diagnosed by the for/in-adverbial test discussed above). As soon as either the verb is -ADDTO ((4b)) or the argument is -SQA $((4 b c))$ or absent altogether $((4 \mathrm{~d}))$, the predicate is atelic. ${ }^{5}$

(4) a. Lisa ate ${ }_{[+\mathrm{ADDTO}]}[\text { the cake }]_{[+\mathrm{SQA}]}(*$ for/in an hour).

b. Lisa saw ${ }_{[-A D D T O}$ [the elephant $]_{[+\mathrm{SQA}]} /$ elephants $[$-SQA] (for/*in an hour).

c. Lisa ate ${ }_{[+\mathrm{ADDTO}]} \operatorname{cakes}_{[-\mathrm{SQA}]}($ for $/ *$ in an hour).

d. Lisa ate $[+\mathrm{ADDTO}]($ for $/ *$ in an hour).

Relating this proposal to the Vendler classes, we see that -ADDTO verbs lead to states, the combination of +ADDTO verbs with a -SQA or no argument to activities ('processes' in Verkuyl's terms), and the combination of +ADDTO verbs with +SQA arguments to accomplishments or achievements (which Verkuyl unites under the label 'events').

Krifka (1989, and subsequent work) proposes a mereological treatment of the aspectual composition of verbs and their arguments, cast in an event semantics framework. He takes the locus of the aspectual value to be in the thematic roles, which express relations between the description of an eventuality, i.e. the predicate contributed by the verb and its modifiers, and the description of the participants in the eventuality, i.e. the predicates contributed by the

\footnotetext{
${ }^{5}$ Verkuyl dubs this the Plus Principle. Following the order of composition of the verb and its arguments, he furthermore observes an asymmetry between the arguments, in the sense that the quantificational properties of the internal argument are to be taken into account first. $\mathrm{He}$ postulates a higher aspectual level, at which external arguments participate in the calculation of telicity, so that a-SQA external argument leads to an atelic interpretation at this higher level (e.g. Children ate the cake for an hour). In the remainder of this section, we will abstract away from the role of the external argument by only using definite singular noun phrases, in order to flesh out the contribution of VP-internal material.
} 
expressions introducing the arguments of the verb. These relations are defined in terms of a homomorphic mapping between the two predicates, also known as event-argument homomorphism. Mapping can take place in both directions, from predicates of events to predicates of arguments and vice versa. The two predicates entering mapping, however, are in an asymmetric relation, reflected for instance in the fact that event predicates are assigned temporal intervals, but predicates of arguments are not.

In (5), for example, the verb to run introduces a thematic role which maps between the reference type of the eventuality it semantically specifies and that of its direct object. If a participant with this thematic role is not provided, the eventuality will be atelic, as in (5a). If such a participant is available, then similarly to Verkuyl's theory, the relevant properties of quantity (in this case of the distance denoted) will be mapped onto the eventuality. This gives us the telic eventuality in (5b) and the atelic one in $(5 c)$.

(5) a. John ran.

b. John ran a mile.

c. John ran miles.

The central property for Krifka's definition of telicity is the property of quantization. A predicate is quantized if and only if whenever it holds of two entities, $x$ and $y$, these two entities do not stand in the proper part relation, as specified in (6).

(6) Quantization: $\forall \mathrm{P} . \mathrm{QUA}(\mathrm{P})<=>[\forall \mathrm{x}, \mathrm{y} \cdot \mathrm{P}(\mathrm{x}) \& \mathrm{P}(\mathrm{y})=>\neg(\mathrm{x}<\mathrm{y})]$

Predicates of events are telic when they are quantized. Nonquantized (cumulative) predicates of events are atelic. There are different ways to compositionally derive a quantized predicate, one of which is described above: when the thematic role maps between a quantized argument and the event predicate.

It is important to note a major difference between Verkuyl's and Krifka's theory, however. For Verkuyl, the quantificational properties of any argument are taken into account when calculating the aspectual properties of a predicate, whereas Krifka explicitly states that this is the case only with arguments bearing a particular 
thematic role, basically those that Dowty (1991) called incremental themes. Hence, his theory initially only captured cases involving incremental theme verbs, such as eat, drink, write. In Krifka (1998) he extends his theory to include motion verbs and change of state verbs (parallels between the ways in which a telic reading comes about with these verb classes had already been noted in Mittwoch 1971; see also Ramchand 1997). For example, goals and sources may entail boundaries for an eventuality and therefore make it quantized, by other means than mapping. Krifka defines these two particular roles in terms of adjacency of intervals applying to all the initial and final subintervals of an eventuality. In order to have its initial and final subintervals adjacent with some other interval, an eventuality needs to be bounded, and is therefore telic as well.

Borer (2005), who proposes an essentially syntactic account for aspectual and argument-structural effects, argues for a modification of Krifka's definition. Still using a mereological approach, she notes that in Krifka's terms, an eventuality that is only bounded on one side, e.g. only with respect to its final subintervals (right-bounded), but not to its initial subintervals (left-unbounded), should be atelic. She provides arguments that this prediction is not empirically met. One of her arguments uses examples as in (6).

(6) run to the square

The eventuality described here is specified for a goal, which imposes a right bound, and is unbounded, as she argues, at its other end. The predicate holds of all the final subintervals of the eventuality it describes: each of the final subintervals is also running to the square. Borer concludes that the relevant property is not quantization, but rather homogeneity (close to Dowty's 1979 views; homogeneity is also defined in Krifka's work), i.e. that it is not telic eventualities that should be defined, but the atelic ones. In her theory, atelic eventualities are defined as those with homogeneous predicates, as defined in (7), and all the other eventualities are telic.

Homogeneity: $\forall \mathrm{P} . \mathrm{HOM}(\mathrm{P}) \Leftrightarrow \mathrm{CUM}(\mathrm{P}) \wedge \operatorname{DIV}(\mathrm{P})$ (a predicate is homogeneous if it is cumulative and divisive) 
Cumulativity: $\forall \mathrm{P} . \mathrm{CUM}(\mathrm{P}) \Leftrightarrow[\forall \mathrm{x}, \mathrm{y} \cdot \mathrm{P}(\mathrm{x}) \wedge \mathrm{P}(\mathrm{y}) \Rightarrow \mathrm{P}(\mathrm{x}+\mathrm{y})]$ (a predicate is cumulative if when it holds of two entities, it also holds of their sum)

Divisiveness: $\forall \mathrm{P} . \mathrm{DIV}(\mathrm{P}) \Leftrightarrow[\forall \mathrm{x}, \mathrm{y} \cdot \mathrm{P}(\mathrm{x})[\exists \mathrm{y} \cdot \mathrm{y}<\mathrm{x} \wedge \mathrm{P}(\mathrm{y})] \wedge$ $[\forall \mathrm{x}, \mathrm{y} \cdot \mathrm{P}(\mathrm{x}) \wedge \mathrm{y}<\mathrm{x} \wedge \mathrm{P}(\mathrm{y}) \Rightarrow \mathrm{P}(\mathrm{x}-\mathrm{y})]$

(a predicate is divisive if when it holds of an entity, it also holds of some parts of that entity, and when it holds of a part of an entity, it also holds of its remaining part)

Arsenijević (2006) gives a yet different view, arguing that all event predicates are either quantized or homogeneous, the former being telic and the latter atelic. He argues that in any context in which these properties can be tested, predicates like the one in (6) involve telic eventualities that come with a context-given starting point, whereas atelic eventualities do not pick one up from the context. More generally, he argues that explicit bounding of one side of the event triggers a contextual bounding of the other.

In the next section, we will see how the idea of event-argument homomorphism receives a new spin, if we assume that the homomorphism involved is one between the eventuality and scalar structures, provided by the verb, its argument, directional PP or other elements.

\subsection{Scales, degrees, generalized paths}

In the previous section we saw that Krifka's (1989) initial theory only covered incremental theme verbs, but that in his 1998 paper he extends the empirical domain to include directed motion and change of state verbs. Hay et al. (1999) open up another way of calculating the aspectual properties of event predicates by introducing the notion of scales, linearly ordered structures associated with event descriptions, and this idea is refined in Kennedy and Levin (2008). In a nutshell, scales can be open/unbounded or closed/bounded (on either side), and this leads to the event being atelic or telic (see also Kearns 2007). The authors focus on degree achievements, a class of verbs that have been notoriously difficult to subsume under any of 
the Vendler classes, since they commonly show variable behavior with respect to standard telicity tests $((8))$.

(8) The soup cooled in/for ten minutes.

They relate the interpretation of the eventuality as atelic or telic to the semantics associated with the adjectival core typically underlying degree achievements. The semantics of adjectives has been treated relying on the notion of degrees or scales (e.g. von Stechow 1984, Kennedy 1999, Rotstein and Winter 2004, Kennedy and McNally 2005, Sassoon 2010). Kennedy and McNally (2005), for example, argue that the semantics of gradable adjectives involves three elements, a measure function, a particular domain in which the measure is occurring, and an ordering relation on that domain. For adjectives that do not appear with degree morphology or modifiers, they posit a covert degree operator 'pos' that measures its argument along a particular dimension in comparison to some standard (see also von Stechow 1984). The properties of the underlying scales, then, lead to a classification of adjectives into closed-scale ones (having minimal and maximal values on the scale, e.g. full, invisible) and open-scale ones (lacking minimal and/or maximal values, e.g. long, old), diagnosed by the (in)compatibility with particular degree modifiers like half or mostly. This, in turn, leads to the interpretation of eventualities described by degree achievements derived from such adjectives as atelic (e.g. fill) or telic (e.g. lengthen), at least by default.

The scale underlying the event description in degree achievements can thus be interpreted as open or closed due to the lexical semantics of the adjectival core of such verbs, but this interpretation can also be affected by context or conventional knowledge. For example, in (9a) the lengthening eventuality is interpreted as telic but in (9b) as atelic, because pants usually come with some standard bounded length, whereas exams can be of any random length (examples from Hay et al. 1999).

(9) a. The tailor almost lengthened the pants.

b. The teacher almost lengthened the exam. 
The different interpretations here are diagnosed with the adverbial modifier almost, which is ambiguous in the telic example a. (the entire eventuality almost took place, or the pants almost became long) but not in the atelic example b. (which only has the first kind of reading) (see also section 3 ).

Hay et al. (1999) argue that this scalar account can be extended to incremental theme verbs, where it is actually not the theme argument itself that participates in the event-argument homomorphism, but rather a particular property of the theme (e.g. size, shape, or others), which then provides a scale again. Similarly, Piñón $(2005,2008)$ and Caudal and Nicolas (2005) propose degree-based accounts of aspect, which they apply to different predicates. Caudal and Nicolas, for instance, distinguish two types of degree scales, a quantity scale (with incremental theme verbs, diagnosed by, e.g., partially in Yannig ate the cake partially) and an intensity scale (accessed by degree modifiers such as perfectly or extremely). We can also think of a scale as a kind of path structure, leading to the idea that the properties of generalized paths provided by the semantics of verbs, their arguments, or particular prepositional phrases, which then also includes motion events (see, for instance, Jackendoff 1996, Zwarts 2006).

Three papers in this volume explicitly base their accounts on degreebased or scalar approaches to aspect and provide good introductions to this topic. Bochnak, for example, picks up Caudal and Nicolas' (2005) observation that there is a need to distinguish between two kinds of scales, when he discusses two readings the English modifier half can have, an eventive and an evaluative reading. Fleischhauer, in turn, discusses degree gradation of German change-of-state verbs by sehr 'very' and, following Kearns (2007), argues for the need to distinguish between a standard telos (associated with non-maximal degrees) and a maximum telos. Finally, Rawlins analyzes English manner adverbs such as quickly or slowly as involving degree predication, along the lines of Kennedy and McNally's (2005) analysis of the semantics of adjectives. We will come back to the details of these three analyses in section 3, when we talk about adverbial modification.

Levin and Rappaport Hovav (2006, and subsequent work) argue that the notion of telicity can in general be associated with scalar change. 
Also in this volume, they make a distinction between scalar change associated with particular verbs (their result verbs), which are basically change of state verbs such as break or open, and non-scalar change (their manner verbs). In the latter case, however, a scale can be introduced by the internal argument (e.g. with incremental theme verbs, on which see also Kennedy 2012) or by a path phrase (with motion events). Again, if the scale is bounded, the eventuality is interpreted as telic. Beavers (2008) builds on this system and adds the important observation that scales can be simple (a transition between two states with no intermediate states, as in achievements) or complex (as in accomplishments). We will return to Levin and Rappaport Hovav's approach in the following section.

\subsection{The contribution of the verb vs. other elements}

Although the concentration has been shifted mainly to the aspectual contribution of internal arguments since Verkuyl's work, properties of the verb itself still have to be taken into account as well. For example, Rothstein (2004) argues that a given verbal predicate licenses a particular event structure, proposing different semantic event structure templates for the four Vendler classes and providing an event semantic implementation of Dowty's (1979) idea to decompose predicates. She takes telicity to be a purely semantic property of predicates at different levels and thus dissociates the Vendler classes from telicity altogether. We will come back to event structure approaches and their merits in section 3.

Event templates, associated with particular verbs, are also employed by Levin and Rappaport Hovav (this volume and previous work). They make a principled distinction between lexicalized meaning, which belongs to the verb itself and is entailed in all its uses, independent of context, contextual meaning, which additionally arises in a particular context, and conventional meaning, conditioned by world knowledge. In previous work (1991, 2006, and Rappaport Hovav and Levin 2010) they argue for a particular constraint on what a verb root can lexicalize, which has come to be known as manner/result complementarity. In particular, they propose that a single verb root can lexicalize manner (non-scalar change) or result 
(scalar change), but not both at the same time. In the contribution to this volume, the authors underline that this complementarity is a constraint rather than a tendency, and they discuss two cases, which have been brought forwards as counterexamples to the manner/result complementarity, namely cut and climb.

Cut is treated as lexicalizing the meaning of result, for which, however, a prototypical manner is often inferred from the context or by convention. In addition, this verb also has clear manner uses, and in these cases Levin and Rappaport Hovav show that the result component is dropped. Conversely, climb is analyzed as a manner verb, with a scalar meaning associated with upward movement resulting from the general context or by convention. They show that climb has some additional uses as a result verb, in which case the manner component is lost entirely. Hence, to conform to their characterization of lexicalized meaning as those components of meaning that are entailed in all uses of a particular verb, they have to analyze verbs like cut and climb as polysemous between manner and result verbs. Once this is done, though, these verbs comply with the manner/result complementarity, and given that there are only few such verbs with multiple senses, this step is argued not to be too costly either.

The two-way distinction between verbs lexicalizing either manner or result (a scalar change) is directly linked to the typological distinction between verb-framed and satellite-framed languages, proposed by Talmy (1985, and subsequent work). Talmy observes that verb-framed languages (e.g. Spanish) typically express the path of a directed motion event on the verb while leaving the manner unexpressed or specified in an adjunct ((10a)). Satellite-framed languages (e.g. English), on the other hand, in describing a directed motion event, typically combine manner of motion verbs with some non-verbal predicate expressing the path (a 'satellite', e.g. prepositional phrases or particles) ((10b)).

(10) a. La botella entró a la cueva (flotando). The bottle entered to the cave (floating) 'The bottle entered the cave floating.'

b. The bottle floated into the cave. 
If we take paths as particular scalar structures (e.g. Zwarts 2005), the correlation with Levin and Rappaport's manner/result complementarity is as follows: A language like Spanish typically makes use of result verbs to describe a directed motion event, whereas a language like English typically employs manner verbs and expresses scalar change in directed motion events by means of PPs or particles (though, as the translation of (10b) shows, English also has result verbs in the motion domain).

Talmy's observations generated various lines of research to determine whether this typological distinction is a mere tendency or a principled difference between the languages in question. Snyder (2001, 2012), for example, proposes the Compounding Parameter as the relevant parameter and argues that a positive setting makes available a particular rule of semantic composition (Generalized Modification in Snyder 2012) which allows a language to create novel endocentric root compounds ((11a)), to combine manner verbs with secondary resultative predicates into one complex predicate associated with an accomplishment interpretation $((11 \mathrm{~b}))$, or to have separable particles $((11 \mathrm{c}))$.

(11) a. faculty lab space committee

b. We hammered the metal flat.

c. They lifted the box up.

Such constructions are possible in English but not in Spanish. Snyder furthermore shows that in English they are also acquired at around the same time. Further implementations of this or related ideas and extensions to various languages can be found in Beck and Snyder (2001), Beck (2005), Gehrke (2008).

Furthermore, it has been suggested that languages of the Spanish type lack directional prepositions altogether (e.g. Folli 2002, Folli and Ramchand 2005, Gehrke 2008), so that these languages naturally employ result verbs to express directed motion events. In addition, it has been proposed - similar to Snyder and the works building on his ideas mentioned above - that particular semantic composition principles or syntactic mechanisms to glue together two predicates into a complex accomplishment predicate are available in satellite-framed languages but not in verb-framed languages (e.g. 
Mateu and Rigau 2002, McIntyre 2004, Harley 2005, Zubizarreta and Oh 2007). Finally, it has been suggested that languages differ in the ways they distribute lexical material over the necessary ingredients of such complex accomplishment predicates (semantically and/or syntactically) (Fábregas 2007, Gehrke 2008, Son and Svenonius 2008). Gehrke (2008), for example, argues that for a verb and an adjectival or prepositional phrase to combine into a complex predicate with an accomplishment interpretation (e.g. (10b), and (11b), but also put the pen in the box) at least one of the two has to express incrementality, i.e. a scale, and that furthermore, in languages of the Spanish type, the scale has to be provided by the verbal predicate. Hence, whereas a language like Spanish does not have strong resultatives or cases like (10b), it still has weak resultatives (e.g. render someone crazy, see also Fong 1997 for respective data from French) or verbs of directed motion combining with locative PPs that merely specify the final location of the movement (of the type arrive at the station), both cases where the verb is essentially a result verb in Levin and Rappaport Hovav's terminology.

\subsection{Aspectual tests, coercion, quantified incremental arguments}

The picture of aspectual composition and aspectual classifications we have painted so far seemed rather neat and clear. However, several important issues have arisen time and time again, such as the validity of the diagnostics to test whether a predicate is telic or not, the influence of the overall context and possible mechanisms to repair aspectual mismatches, also known as coercion, or the fact that event-argument homomorphism models work well when we are dealing with (in)definite or bare nouns, but get more complicated when we take quantified NPs into account.

Returning to the temporal adverbial test exemplified in (2), it has been noted that under certain contexts the particular adverbials are acceptable with classes that otherwise do not allow them. For example, iterative contexts make for-adverbials acceptable with accomplishments and achievements. This has been captured by the intuition that an iteration of otherwise bounded (or telic) events can 
be seen as unbounded overall, in which case a for-adverbial is applicable again. Furthermore, with some telic predicates the foradverbial can take scope not over the entire event, but only over the consequent state, as in (12).

(12) She lent him the book for two days.

Inchoative or bounded reinterpretations of states and activities, in turn, render in-adverbials acceptable again. Such reinterpretations are commonly treated as instances of coercion (in the sense of Moens and Steedman 1988; see, for instance, de Swart 1998). Coercion alters the interpretation that is lexically associated with a given predicate in some way so to fit the requirements of the particular adverbials. This is usually done by adding something to the event description, such as an initial and/or final bound, or also a preparatory phase, as we will see in some of the following examples. Furthermore, it has been noted that while accomplishments and achievements both allow in-adverbials, the effects are quite different. Whereas with accomplishments, these adverbials intuitively measure the time the event took ((13a)), with achievements, it measures some time preceding the actual event $((13 b))$.

(13) a. run a mile in an hour

b. reach the summit in an hour

Hamm and van Lambalgen (2005) therefore argue that also achievements undergo aspectual coercion in order to be compatible with in-adverbials, which adds a preparatory phase to the event ('additive coercion' in their terminology).

Bott (this volume) provides a good introduction to the phenomenon of aspectual mismatches, which can be repaired in some cases (resulting in coercion), but lead to ungrammaticality in other cases. In order to determine at what level of the sentence an atomic event unit is constructed, he investigates the processing of particular aspectual mismatch and coercion cases, such as the combination of achievements and accomplishments with for-adverbials, as well as 
achievements with in-adverbials. Coercion is also addressed in Martin (this volume).

Also the progressive test is not perfect, since in some contexts and in particular with some predicates, the progressive is more acceptable with classes that should otherwise not allow it. For example, the achievement in (14a) is not as bad as (3a), repeated here as (14b). ${ }^{6}$

(14) a. ?They are arriving at the station.

b. *He was finding a key.

Rothstein (2004) proposes that in such cases achievements are coerced into accomplishments by adding a preparatory phase, which is similar to Hamm and van Lambalgen's (2005) additive coercion discussed above. Furthermore, state predicates like sit, stand, lie, which Dowty (1979) calls interval statives and Bach (1986) dynamic states, are fully acceptable with the Progressive. Defining the class of states is notoriously difficult and has led to different proposals how to handle them, as was briefly discussed in the previous section (see also Mittwoch 2005).

Mittwoch (this volume) provides a critical survey of the criteria used to distinguish between accomplishments and achievements, including the two discussed here, as well as other tests, such as entailment patterns with progressive and simple tenses, ambiguity with almost, modification by halfway, or the notions of telos, result state, and subinterval property. She argues that accomplishments and achievements are distinguished at the level of VP, whereas the status of states and achievements is determined at the level of the verb alone. Based on Parsons' (1990) and Kratzer's (2004) analyses, Mittwoch shows that the subinterval property criterion (Bennett and Partee 1972), which is supposed to draw the line between activities and accomplishments, needs revision since in fact accomplishments are homogeneous up to culmination, which is similar to the point

\footnotetext{
6 This difference follows from analyses of the progressive that build volitionality or intentionality into its semantics: one can intentionally arrive somewhere but one cannot intentionally find something (see Portner 2011 for a summary of different approaches to the semantics of the progressive). Furthermore, if no control by an agent is taken as one of the defining features of achievements (e.g. in Dowty 1979), the predicate in (10a) should not count as an achievement, although it is commonly assumed to be one, since an arrival takes place instantaneously.
} 
raised by Borer (2005) above. In addition, activities delimited by cardinal quantifiers are shown to also lack the subinterval property. The criterion of indirect measurement of temporal extent by in- and for-adverbials is argued not to sufficiently distinguish between accomplishments and activities either, as we have already seen in some examples above, but also in (15).

(15) The doctor examined the patient (for/in an hour).

Moreover, in-adverbials may be problematic with predicates whose incremental arguments have vague quantifiers (e.g. some, a few, many/a lot of, at most, at least), and Mittwoch argues that the predicates with such selected non-specific DPs are defective accomplishments. Already Zucchi and White (2001) noted that while particular quantified DPs do not meet the formal definitions of quantizedness, they nevertheless seem to bring about a telic interpretation of the predicate involved. In order to provide some answers as to why such conflicts and irregularities arise, Mittwoch also discusses the similarities, differences and mutual relations between activities and accomplishments as well as between activities and achievements, especially in the so-called coerced readings where achievements behave like accomplishments.

We will now turn to adverbial modification in the domain of eventualities.

\section{Adverbial modification}

One of the main motivations for Davidson (1967) to introduce the event argument came from adverbial modification, since this move allowed to interpret such modifiers intersectively, as modifiers of the event itself, and to capture particular entailment patterns between sentences with and without adverbials. These insights were preserved under the so-called Neo-Davidsonian turn, starting with Higginbotham (1985) and Parsons (1990). Their innovations include the addition of event participants via thematic roles, the association of non-action predicates, such as states and non-verbal predicates, with an event variable, and the breaking down of events into 
subevents, in particular processes, states and combinations of these (see also Rawlins this volume, for a good introduction to NeoDavidsonian event semantics).

Parsons (1990), for example, observes that his innovations still capture the entailment relations between sentences like those in (16).

(16) a. Brutus stabbed Caesar in the back with a knife.

b. Brutus stabbed Caesar in the back.

c. Brutus stabbed Caesar with a knife.

d. Brutus stabbed Caesar.

(16a) entails the conjunction of (16b) and (16c), but not vice versa. Either of (16b) or (16c) alone entails (16d). These facts logically follow from Parsons' representation of the respective sentences in (17).

(17) a. (ヨe)[Stabbing(e) \&Subj(e,B) \&Obj(e,C) \&In(e,b) $\& W i t h(e, k)]$

b. (ヨe)[Stabbing(e) \&Subj(e,B) \&Obj(e,C) \&In(e,b)]

c. $\quad(\exists e)[\operatorname{Stabbing}(\mathrm{e}) \& \operatorname{Subj}(\mathrm{e}, \mathrm{B}) \& \operatorname{Obj}(\mathrm{e}, \mathrm{C}) \& \mathrm{With}(\mathrm{e}, \mathrm{k})]$

d. ( $\quad$ e $)[\operatorname{Stabbing}(\mathrm{e}) \& \operatorname{Subj}(\mathrm{e}, \mathrm{B}) \& \operatorname{Obj}(\mathrm{e}, \mathrm{C})]$

Breaking down events into subevents and having adverbial modifiers access different subevents opens up the way to treat ambiguities with particular adverbial modifiers in terms of scope and thus as structural instead of lexical ambiguities. Such ambiguities arise, for example, with almost (e.g. Pustejovsky 1991, von Stechow 1995, Rapp and von Stechow 1999; see also (9)), again (e.g. von Stechow 1996, 2003, Beck 2005), adverbs of space and time (e.g. Rawlins this volume, see section 3.3), or also for-adverbials (see (1) vs. (12)) and locative PPs (e.g. Gehrke 2008).

Decomposing predicates goes back to Dowty (1979) who did not make use of event arguments, though. Dowty proposes three predicates, DO, CAUSE, BECOME, which are combined in different ways to arrive at the four Vendler classes. States are treated as simple predicates involving none of these three predicates, activities additionally involve DO (i.e. the immediate control of an agent), achievements BECOME (i.e. a change of state), and accomplishments 
all three (i.e. an agent causing a theme to undergo a change of state). His idea of decomposing predicates has been reformulated in event semantic terms, so that an event (the macroevent) can be structurally complex and decomposable into particular subevents. Subevents are associated with CAUSE, DO or BECOME predicates, or related notions such as preparatory phase, initiating state, process, transition, culmination, consequent, result(ant), or target state and the like (see Moens and Steedman 1988, Parsons 1990, Pustejovsky 1991, von Stechow 1996, Higginbotham 2000, Rothstein 2004, Kratzer 2005, Beck 2005, Ramchand 2008, among many others).

For example, under Parsons' (1990) bi-eventive analysis of causatives, a modifier like behind the museum in (18a) can modify either the causing subevent (e), meaning Mary was behind the museum and flew her kite, or the caused subevent (e'), meaning Mary flew her kite, which ended up behind the museum.

(18) a. Mary flew her kite behind the museum.

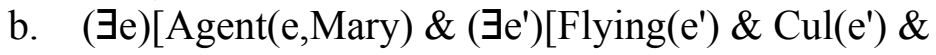

Theme(e',Kite) \&Behind(_,museum) \& CAUSE (e,e')]].

This is captured in the analysis in (18b) by leaving the event argument position of behind unspecified.

A similar example of ambiguity with modified bi-eventives arises for again. Here, the ambiguity is between a repetitive ((19a)) and a restitutive reading ((19b)) (examples from von Stechow 1996).

(19) Clyde cleans his boots again.

a. ... and Clyde has cleaned his boots before.

b. ... and his boots were clean before.

Von Stechow (1996) proposes an event structure account of this ambiguity, under which again has the same lexical semantics (roughly meaning something like repetition), but different scope with respect to the subevents associated with the predicate in question. Under the restitutive reading, again is taken to modify the lower subevent (the result state), which leads to the interpretation that the boots have been in a clean state before, whereas under the repetitive reading, it modifies the higher causing subevent, leading 
to the interpretation that Clyde has performed the action of cleaning his boots before. With activities, only the repetitive reading is attested, which follows automatically, if activities only have one subevent (the one associated with a process) (but see also Jäger and Blutner 2001 for a criticism of this account, and von Stechow 2003 for a reply).

Hence, we see that adverbial modifiers can be used as a diagnostics for the structural complexity of a given eventuality. Under the assumption that accomplishments are telic, modifiers like again and almost have also been used to diagnose whether an eventuality is telic or not, since the ambiguity then only arises with telic eventualities (see also Mittwoch this volume). We have already seen that other adverbial modifiers, such as in- and for-adverbials serve the same purpose. In the following, we will describe how papers in this volume make use of adverbial modifiers to diagnose for particular properties of eventualities.

\subsection{Interaction with event structure}

In section 2, we mentioned that there is much debate about the status of states, and especially whether they contain an event argument in their argument structure. Based on the unavailability of manner modifiers with (most) states, among other diagnostics, Katz (2003, 2008) and Maienborn (2005) argue that states should not be associated with an event argument. Furthermore, it is often assumed that non-agentive achievements (e.g. find) do not allow particular types of manner modifiers, precisely because they lack agentivity. Martin (this volume) addresses the issue that nevertheless, combinations of achievements as well as object experiencer verbs, a subclass of states, with dispositional adverbs (e.g. cleverly) and psychological adverbs (e.g. sadly), two subclasses of manner modifiers, are widely attested in corpus data $((20))$.

(20) a. He won the race quite cleverly. 
b. Pierre a asticieusement intéressé ses étudiants à Pierre has craftily interested his students to

la logique.

the logic

Mostly based on data from French, Martin argues that such verbs are weakly agentive, rather than non-agentive, and proposes a more fine-grained analysis of the adverbs in question, by distinguishing transparent from neutral dispositional or psychological adverbs (patiemment 'patiently' / anxieusement 'anxiously', and intelligemment 'intelligently' / tristement 'sadly', respectively). Transparent adverbs are argued to lexically encode a mental state in all their uses, whereas lexical adverbs express it only optionally and can thus have a pure manner reading (and sometimes also a result reading). She shows that neutral adverbs are less problematic with weakly agentive verbs, since they can express pure manner or result readings. More problems arise with transparent adverbs, and Martin argues that in these cases, achievement predicates are coerced into durative (and agentive) predicates ((21a)), whereas object experiencer verbs get a causative (and agentive) reading $((21 \mathrm{~b}))$.

(21) a. He patiently found the download link.

b. He cleverly interested the investors in his product.

What we can conclude from this paper is that by disentangling manner from agentivity, the argument against event arguments for states becomes much weaker, since it shows that states (e.g. those associated with object experiencer verbs) might be incompatible with agentivity or causation, but not necessarily with manner per se. It furthermore stresses the need to question each diagnostics and what it actually diagnoses for, and possibly include some additional tests for properties like causation, intention, agentivity, manner, result etc.

Adverbs have also been employed to diagnose for different scale structure underlying eventualities. We now turn to such approaches. 


\subsection{Interaction with scales}

Focusing on VPs headed by incremental theme verbs and on the degree modifier half in English, Bochnak (this volume) argues that there are two distinct sources of scalarity within the verb phrase, a quantity scale and a quality scale. These are diagnosed by two readings of the modifier half, namely the eventive ((22a)) and the evalutative one ((22b)) (our descriptions).

(22) John half ate the apple.

a. John ate half of the apple.

b. What John did, can only halfway be described as an apple-eating eventuality.

Bochnak argues that eventive half is possible only when a telic interpretation of the sentence is also possible, hence with a quantized incremental theme. This is so because the eventive use of half requires a bounded nominal argument on which to base a fully closed scale structure. In particular, eventive half functions as a degree term that targets a quantity-based scale and which is tightly related to nominal part structure, since it measures out the quantity of the incremental argument (e.g. the quantity of apple parts that are eaten). Evaluative half, on the other hand, functions as a degree term that makes a comment about the degree to which the eventuality represents a prototypical eventuality (e.g. eating), hence it targets a quality-based scale. Assuming that non-quantized (cumulative) incremental themes yield atelic eventualities, Bochnak shows that evaluative half is unmarked for telicity, given that this reading is still available with such event descriptions. Since quality scales are lexicalized by incremental theme verbs, evaluative half combines directly with the verb to create a compound verb with a meaning of half $\mathrm{V}$. In other cases, it is argued that a null verbal pos morpheme supplies the degree argument with a contextual standard (see section 2.2 for the adjectival counterpart).

Another way to use adverbs to diagnose for the type of underlying scale is found in Fleischhauer (this volume). Based on Bolinger (1972), he distinguishes extent gradation, measuring the duration or frequency of the event, and degree gradation, measuring a gradable 
property lexicalized by the verb. He discusses the fine structure of the boundaries of telic eventualities taking a scalar approach, and argues that there are two types of such boundaries, namely those introducing a standard value, and those corresponding to an extreme value of the relevant property or degree. In particular, he shows how aspect interacts with degree gradation of change of state verbs, i.e. verbs that express a change in a certain dimension of the referent of the theme argument.

Fleischhauer focuses on the German degree modifier sehr 'very', and to a lesser extent on items with the same meaning in Russian (očen') and French (beaucoup). Unlike in English, these items can also apply to verbal predicates, then meaning something like "very much, a lot', and the effect on the interpretation of gradation of change of state verbs is the same: sehr changes the truth conditions and the referential properties of a predication. The author assumes a subdivision of accomplishments into gradable and non-gradable ones (similar to the distinction between simple and complex scales in Beavers 2008; see section 2.2) and shows that there is a distinction between telicity (potential endpoint) and boundedness (temporal limitation of an eventuality) of graded degree achievements and of accomplishments. He rejects the analysis of telicity in terms of a maximal scale value (e.g. Caudal and Nicolas 2005), and, following Kearns (2007), distinguishes two types of telos: a standard telos, which is an endpoint on a scale or the onset of a result state, and a maximum telos, which is a maximal scale value. Among accomplishments, only those can be modified by sehr that have their telos on the same scale along which they are graded, hence the scale targeted by sehr, and moreover, their aspectual type is related both to the standard and to the maximal value on the scale. In the following section, we see another way in which adverbs can interact with eventualities, namely when we take a look at Rawlins' account of adverbs of space and time.

\subsection{Interaction with temporal structure}

Rawlins (this volume) discusses English adverbs like slowly and quickly, which Cresswell (1977) dubbed adverbs of space and time. 
He observes that these adverbs allow two kinds of measure phrases in the comparative, characterizing a ratio reading $((23 a))$, which he essentially treats as a manner reading, and a temporal extent reading $((23 b))$.

(23) a. Alfonso ran to the park 2 miles per hour more quickly than Joanna.

b. Alfonso ran to the park 2 minutes more quickly than Joanna.

He notes that this is an unusal pattern, given that adjectives only allow one type of measure phrase modification, which is determined by the dimension of the particular adjective, and ideally this should also hold for the related adverbs.

To account for the data in a way that does not treat the adverbs as ambiguous but rather analogous to the respective adjectives, he proposes that they are distributive degree predicates of events, which measure its temporal extent only. He argues that the different readings (ratio/manner vs. extent) and hence the availability of different measure phrase modifiers follow from the interaction of distributivity with the particular lexical aspect of the verbal predicate involved, in cases the adverb attaches low, or with narrative discourse, in cases the adverb attaches high.

For instance, achievements (as well as semelfactives) only allow the extent reading ((24a)), whereas activities only allow the manner/ratio reading $((24 b))$. Accomplishments, in turn, allow both readings $((23))$.

(24) a. Alfonso reached the peak $\{10$ minutes / $* 2$ miles per hour\} more quickly than Henry.

b. *Alfonso ran $\left\{{ }^{*} 10\right.$ minutes / 10 miles per hour $\}$ more quickly than Joanna.

Rawlins explains this pattern by arguing that distributivity needs to apply to atoms. For the extent reading to be possible, the distribution takes place over the event structure, in which case the entire event is measured, which in the case of (24a) is trivial. The ratio/manner reading, in turn, distributes over the (unstable) atoms of a running 
(driving etc.), rather than over the entire event, which is not an atom with activities of the type in (24b), since it is not quantized. This reading gives the impression of a manner modification, since it tells us more about the agent involved in the process. Accomplishments allow both readings, since they combine a process (with unstable atoms) with a culmination (the whole event is atomic, since it is quantized). ${ }^{7 \cdot 8}$

High-attached adverbs of space and time, in turn, modify a whole clause and only allow extent readings and modifiers. Rawlins argues that these adverbs measure the time from some previous event until the event described in the modified sentence, which is why they are odd out of context, e.g. as the first sentence in a discourse ((25)).

(25) \#Slowly, the instructor set up his computer.

He calls such events in discourse 'narrative events', which include at least the described event, and conjectures that narrative events are always quantized. This explains why they only allow the extent reading: the event has a consistent part-whole structure that is determined independently of lexical aspect. Ordering and immediateness are two characteristics of narrative discourse that may explain the distribution of these adverbs. The former means that the temporal order of events described in a narrative discourse matches the utterance order, while the latter means that if $e_{1}$ precedes $e_{2}$ in a narrative event sequence, by default $e_{2}$ closely or immediately follows $e_{1}$.

In the next and final section of this introduction, we take a look at psycholinguistic investigations into the domain of events.

\footnotetext{
${ }^{7}$ Thus, this treatment of the ambiguity as a structural rather than a lexical one is essentially along the lines as that of the ambiguity with again and other modifiers discussed in the beginning of this section.

${ }^{8}$ Rawlins notes that states do not allow for adverbs of space and time altogether (with or without measure phrase modifiers) and suggests that this can be explained under an analysis like Katz's (2003), though he remains agnostic as to the question whether or not states are associated with an event argument.
} 


\section{Experimental studies of event predicates}

Apart from investigations into the acquisition of phenomena related to aspect and to the syntax and semantics of events in general (see, for instance, Slabakova 2001, van Hout 2008), there are only few psycholinguistic studies of such issues, and this is a fairly new field. Previous processing studies aimed at providing evidence for the assumption that eventualities can differ in structural complexity (McKoon and MacFarland 2000, 2002, Gennari and Poeppel 2003, Mobayyen and de Almeida 2005). Gennari and Poeppel (2003), for example, compare the processing speed of eventive (inspect, explore, criticize, invent) versus stative verbs (dislike, appreciate, admire) in a lexical decision paradigm, employing a self-paced reading technique. They start out from the assumption that eventive predicates have a more complex semantics and syntax, in the sense that eventive predicates entail simpler conceptual units such as CAUSE, BECOME, or CHANGE and resulting STATE, corresponding to the event's internal dynamics they denote, whereas stative verbs lack such entailments. The results indicate that eventive verbs take longer to process than stative verbs.

There is also some, though not fully conclusive evidence that coercion and type shifting operations in the domain of events add additional processing complexity (Traxler et al. 2005, Piñango et al. 2006, Bott 2008, Brennan and Pylkkänen 2008). Bott (this volume) provides a good introduction to this topic and follows up on his previous research in this domain. The overall aim of his paper is to facilitate the choice between two hypotheses with regard to the way lexical aspect is computed: (i) incrementally, i.e. word by word, according to the Incremental Aspectual Interpretation Hypothesis (IAIH), or (ii) when the verb has all its arguments, according to the Late Aspectual Interpretation Hypothesis (LAIH). ${ }^{9} \mathrm{He}$ conducts an off-line study, two self-paced reading experiments and an eyetracking experiment to test the effects of aspectual mismatch and coercion in German, which arise with particular temporal adverbials in combination with accomplishment and achievement predicates (as

\footnotetext{
${ }^{9}$ A third hypothesis, the Complete VP Hypothesis, is introduced at a later point but we will ignore it here, since in the conclusion it turns out to be incorrect and overall less relevant.
} 
outlined in section 2.4). To test the size of the domain in which mismatch and coercion effects arise, different word orders were employed, where the stimulus for the mismatch or coercion appeared either after the verb and all its arguments, or at some point before. The results demonstrate that LAIH is the most suitable hypothesis: Aspectual mismatches were detected only after the complete verb-argument structure was processed, whereas no mismatch or coercion effects were found when the verb had not received all its arguments. Bott argues that the results further show that there are in fact two types of incrementality: immediate processing (which is the case for mismatch and coercion) and wordby-word processing (what is commonly assumed in the literature on processing). As for lexical aspect, it seems to be determined at a more global, rather than the lexical level, as it depends on a bigger processing domain than the word.

Bott's findings also fit previous behavioral studies of subatomic event semantics, which have suggested that verbal telicity is not purely semantic because telic verbs (e.g., catch, fall) activate specific syntactic (or event structure) templates. As a matter of fact, it seems that telic verbs prime or re-activate the patient argument, be they intransitive/unaccusative, transitive, or ambitransitive (Tenny 1987, van Hout 2001). Moreover, they provide a temporal reference point for further aspectual computations and they imply the existence of an affected event participant.

Malaia et al. (this volume) address certain questions which have been left unanswered by previous behavioral studies, such as the exact relation between online comprehension and verbal event structure, the influence of the semantic and syntactic properties of the verb in the assignment of thematic roles, and the continuous or sequential nature of this processing during comprehension. They conducted two experiments, whose results show, on the one hand, that telic verbs activate a syntactic structure with an obligatory internal argument, which serves as a salient cue for thematic role assignment during online linguistic computations. On the other hand, the study reveals that the priming of the patient by telic verbs has to do with neurocognitive processes related to the attention and cognitive load, while the event templates evoked by telic verbs are utilized simultaneously with word-category assessment. 


\section{Conclusion}

This chapter introduced the current state of the art of event semantics and provided background information on issues addressed in the papers of this volume, sketching in how far they relate to one another. As we have shown, the contributions included here are concerned with one central issue, the subatomic semantics of event predicates, in at least one of the three following subjects: aspectual composition, decompositional approaches to aspect and adverbial modification. We hope you are now prepared to dive into the nitty bitty details of each paper individually.

Acknowledgments. We owe special thanks to Henriëtte de Swart for comments on an earlier version of this introduction, which led to major improvements. We also thank the audience of the workshop that initiated the work on this volume. This volume would not be the same without our external reviewers Olga Borik, Jonathan Brennan, Regine Eckardt, Nino Grillo, Jaume Mateu and Louise McNally. Our work on this book was supported by the following grants from the Spanish Ministry of Science and Innovation: 'Natural language ontology and the semantic representation of abstract objects' (FFI2010-15006, Louise McNally), JCI-2008-2699 \& RYC2011-08771 (Boban Arsenijević), and JCI-2010-08581 (Berit Gehrke).

\section{References}

Arsenijević, Boban. 2006. Inner Aspect and Telicity. Utrecht: LOT.

Bach, Emmon. 1981. On time, tense and aspect: An essay in English metaphysics. In Radical Pragmatics, ed. Peter Cole, 63-81. New York: Academic Press.

Bach, Emmon. 1986. The algebra of events. Linguistics and Philosophy 9:5-16.

Beavers, John. 2008. Scalar complexity and the structure of events. In Event Structures in Linguistic Form and Interpretation, ed. Johannes Dölling, Tatjana Heyde-Zybatow, and Martin Schäfer, 245-268. Berlin: de Gruyter.

Beck, Sigrid. 2005. There and back again: A semantic analysis. Journal of Semantics 22:351.

Beck, Sigrid, and William Snyder. 2001. The resultative parameter and restitutive again. In Audiatur Vox Sapientiae: A Festschrift for Arnim von Stechow. Ed. Caroline Féry and Wolfgang Sternefeld, 48-69. Berlin: Akademie Verlag.

Bennett, Michael and Partee, Barbara. 1972, Toward the logic of tense and aspect in English. Report for the System Development Corporation, Santa Monica, CA.

Bolinger, Dwight. 1972. Degree Words. The Hague: Mouton.

Borer, Hagit. 2005. Structuring Sense. Vol. II: The Normal Course of Events. Oxford: Oxford University Press.

Bott, Oliver. 2008. The Processing of Events. PhD Dissertation, Tübingen University.

Brennan, Jonathan, and Liina Pylkkänen. 2008. Processing events: Behavioral and neuromagnetic correlates of aspectual coercion. Brain and Language 106.2:132-143.

Carlson, Gregory N. 1977. Reference to Kinds in English. Ph.D. Dissertation, UMass. 
Caudal, Patrick, and David Nicolas. 2005. Types of degrees and types of event structures. In Event Arguments: Foundations and Applications, ed. Claudia Maienborn and Angelika Wöllstein, 277-300. Tübingen: Niemeyer.

Comrie, Bernard. 1976. Aspect: An Introduction to the Study of Verbal Aspect and Related Problems. Cambrige: Cambridge University Press.

Cresswell, Max. 1977. Adverbs of space and time. In Formal Semantics and Pragmatics for Natural Languages, ed. F. Guenthner and Siegfried J. Schmidt, 171-199.

Davidson, Donald. 1967. The logical form of action sentences. In The Logic of Decision and Action, ed. Nicholas Resher, 81-95. Pittsburgh: University of Pittsburgh Press.

Dowty, David. 1979. Word Meaning and Montague Grammar: The Semantics of Verbs and Times in Generative Semantics and in Montague's PTQ. Dordrecht: Reidel.

Dowty, David. 1991. Thematic proto-roles and argument selection. Language 67.3:547619.

Fábregas, Antonio. 2007. The exhaustive lexicalisation principle. Nordlyd Tromsø Working Paper on Language and Linguistics 34.2: 165-199.

Folli, Raffaella. 2002. Constructing Telicity in English and Italian. Ph.D. Dissertation, University of Oxford.

Folli, Raffaella, and Gillian Ramchand. 2005. Prepositions and results in Italian and English: An analysis from event decomposition. In Perspectives on Aspect, ed. Henk Verkuyl, Henriëtte de Swart and Angeliek van Hout, 81-105. Dordrecht: Springer.

Fong, Vivienne. 1997. The Order of Things: What Directional Locatives Denote. Ph.D. Dissertation, Stanford University.

Gehrke, Berit. 2008. Ps in Motion: On the Semantics and Syntax of Ps and Motion Events. Utrecht: LOT.

Gennari, Silvia, and David Poeppel. 2003. Processing correlates of lexical semantic complexity. Cognition 89.1:27-41.

Hamm, Fritz, and Michiel van Lambalgen. 2005. The Proper Treatment of Events. Malden, MA: Blackwell.

Harley, Heidi. 2005. How do verbs get their names? Denominal verbs, manner incorporation and the ontology of verb roots in English. In The Syntax of Aspect: Deriving Thematic and Aspectual Interpretation, ed. Nomi Erteschik-Shir and Tova Rapoport, 42-64. Oxford: Oxford University Press.

Hay, Jennifer, Chris Kennedy, and Beth Levin. 1999. Scalar structure underlies telicity in 'degree achievements'. In Proceedings of SALT IX, ed. Tanya Matthews and Dan Strolovitch, 127-144. CLC Publications: Ithaca.

Higginbotham, James. 1985. On semantics. Linguistic Inquiry 547-593.

Higginbotham, James. 2000. On events in linguistic semantics. In Speaking of Events, ed. James Higginbotham, Fabio Pianesi, and Achille Varzi, 49-79. Oxford: Oxford University Press.

van Hout, Angeliek. 2008. Acquisition of perfective and imperfective aspect in Dutch, Italian and Polish. Lingua 118(11): 1740-1765.

Jackendoff, Ray. 1996. The proper treatment of measuring out, telicity, and perhaps even quantification in English, Natural Language and Linguistic Theory 14:305-354.

Jäger, Gerhard, and Reinhard Blutner. 2003. Competition and interpretation: The German adverb wieder ('again'). In Modifying Adjuncts, ed. Ewald Lang, Claudia Maienborn and Catherine Fabricius-Hansen, 393-416. Berlin: de Gruyter.

Kamp, Hans, and Uwe Reyle. 1993. From Discourse to Logic: Introduction to Modeltheoretic Semantics of Natural Language, Formal Logic and Discourse Representation Theory. Dordrecht: Kluwer. 
Katz, Graham. 2003. Event argument, adverb selection, and the Stative Adverb Gap. In Modifying Adjuncts, ed. Ewald Lang, Claudia Maienborn and Catherine FabriciusHansen, 455-474. Berlin: de Gruyter.

Katz, Graham. 2008. Manner modification of state verbs. In Adjectives and Adverbs in Semantics and Discourse, ed. Louise McNally and Christopher Kennedy, 220-284. Oxford: Oxford University Press.

Kearns, Kate. 2007. Telic senses of deadjectival verbs. Lingua_117:26-66.

Kennedy, Christopher. 1999. Projecting the Adjective: The Syntax and Semantics of Gradability and Comparison. New York: Garland.

Kennedy, Christopher. 2012. The composition of incremental change. In Telicity, Change, and State: A Cross-Categorial View of Event Structure, ed. Violeta Demonte and Louise McNally, 103-121. Oxford: Oxford University Press.

Kennedy, Christopher, and Beth Levin. 2008. Measure of change: The adjectival core of verbs of variable telicity. In Adjectives and Adverbs in Semantics and Discourse, ed. Louise McNally and Christopher Kennedy, 156-182. Oxford: Oxford University Press.

Kennedy, Christopher, and Louise McNally. 2005. Scale structure, degree modification, and the semantic typology of gradable predicates. Language 81:345-381.

Kratzer, Angelika. 1995. Stage-level and individual-level predicates. In The Generic Book, ed. Gregory N. Carlson and Francis J. Pelletier, 125-175. Chicago: University of Chicago Press.

Kratzer, Angelika. 2004. Telicity and the meaning of objective case. In The Syntax of Time, ed. Jacqueline Guéron and Jacqueline Lecarme, 389-424. Cambridge, MA: MIT Press.

Kratzer, Angelika. 2005. Building resultatives. In Event Arguments: Foundations and Applications, ed. Claudia Maienborn and Angelika Wöllstein, 177-212. Tübingen: Niemeyer.

Krifka, Manfred. 1989. Nominal reference, temporal constitution and quantification in event semantics. In Semantics and Contextual Expression, ed. Johan van Benthem, Renate Bartsch and Peter van Emde Boas, 75-115. Dordrecht: Foris.

Krifka, Manfred. 1998. The origins of telicity. In Events and Grammar, ed. Susan Rothstein, 197-235. Dordrecht: Kluwer.

Lasersohn, Peter. 1990. A Semantics for Groups and Events. New York: Garland Publishing.

Levin, Beth, and Malka Rappaport Hovav, 1991. Wiping the slate clean: A lexical semantic exploration. Cognition 41:123-151.

Levin, Beth, and Malka Rappaport Hovav. 2006. Constraints on the complexity of verb meaning and VP structure. In Between 40 and 60 Puzzled for Krifka, ed. Hans-Martin Gärtner, Regine Eckardt, Renate Musan and Barbara Stiebels.

Maienborn, Claudia. 2005. On the limits of the Davidsonian approach: The case of copula sentences. Theoretical Linguistics 31.3:275-316.

Mateu, Jaume, and Gemma Rigau 2002. A minimalist account of conflation processes: Parametric variation at the lexicon-syntax interface. In Theoretical Approaches to Universals, ed. Artemis Alexiadou, 211-236. Amsterdam: John Benjamins.

McIntyre, Andrew. 2004. Event paths, conflation, argument structure and VP shells. Linguistics 42.3:523-571.

McKoon, Gail, and Talke Macfarland. 2000. Externally and internally caused change of state verbs. Language 76.4:833-858.

McKoon, Gail, and Talke Macfarland. 2002. Event templates in the lexical representations of verbs. Cognitive Psychology 45.1:1-44.

ter Meulen, Alice G. B. 1995. Representing Time in Natural Language. The dynamic interpretation of tense and aspect. Cambridge, MA: Bradford Books, MIT Press. 
Mittwoch, Anita. 1971. Optional and Obligatory Verbal Complements in English. Ph.D. Dissertation, SOAS, London.

Mittwoch, Anita. 2005. Do states have Davidsonian arguments? Some empirical considerations. In Event Arguments: Foundations and Applications, ed. Claudia Maienborn and Angelika Wöllstein, 69-88. Tübingen: Niemeyer.

Mobayyen, Forouzan, and Roberto G. de Almeida. 2005. The influence of semantic and morphological complexity of verbs on sentence recall: Implications for the nature of conceptual representation and category-specific deficits. Brain and Cognition 57.2:168171.

Moens, Marc, and Mark Steedman. 1988. Temporal ontology and temporal reference. Computational Linguistics 14.2:15-28.

Parsons, Terence. 1990. Events in the Semantics of English: A Study in Subatomic Semantics. Current Studies in Linguistics Series 19. Cambridge, MA: MIT Press.

Piñango, Maria M., Jennifer Mack and Ray Jackendoff. 2006. Semantic combinatorial processes in argument structure: Evidence from light-verbs. In Proceedings of the Annual Meeting of the Berkeley Linguistics Society (=BLS) 32.

Piñón, Christopher. 2005. Adverbs of completion in an event semantics. In Perspectives on Aspect, ed. Henk Verkuyl, Henriëtte de Swart and Angeliek van Hout, 146-166. Dordrecht: Springer.

Piñón, Christopher. 2008. Aspectual composition with degrees. In Adjectives and Adverbs in Semantics and Discourse, ed. Louise McNally and Christopher Kennedy, 183-219. Oxford: Oxford University Press.

Portner, Paul. 2011. Perfect and progressive. In Semantics: An International Handbook of Natural Language Meaning (Vol. 2), ed. Klaus von Heusinger, Claudia Maienborn, and Paul Portner, 1217-1261. Berlin: de Gruyter.

Pustejovsky, James. 1991. The syntax of event structure. Cognition 41:47-81.

Pustejovsky, James. 1995. The Generative Lexicon. Cambridge, MA: MIT Press.

Ramchand, Gillian. 1997. Aspect and Predication. Oxford: Clarendon.

Ramchand, Gillian. 2008. Verb Meaning and the Lexicon: A First Phase Syntax. Cambridge: Cambridge University Press.

Rapp, Irene, and Arnim von Stechow. 1999. 'Almost' and the Visibility Parameter for Functional Adverbs. Journal of Semantics 16. 149-204.

Rappaport Hovav, Malka, and Beth Levin. 2010. Reflections on Manner/Result complementarity. In Lexical Semantics, Syntax, and Event Structure, ed. Malka Rappaport Hovav, Edit Doron, and Ivy Sichel, 21-38. Oxford: Oxford University Press.

Reichenbach, Hans. 1947. Elements of Symbolic Logic. London: MacMillan.

Rothstein, Susan. 2004. Structuring Events: A Study in the Semantics of Lexical Aspect. Oxford: Blackwell.

Rotstein, Carmen, and Yoad Winter. 2004. Total adjectives vs. partial adjectives: Scale structure and higher-order modification. Natural Language Semantics 12:259-288.

Sassoon, Galit Weidman. 2010. The degree functions of negative adjectives. Natural Language Semantics 18:141-181.

Slabakova, Roumyana. 2001. Telicity in the Second Language. Amsterdam: John Benjamins.

Smith, Carlota S. 1991. The Parameters of Aspect. Dordrecht: Kluwer.

Snyder, William. 2001. On the nature of syntactic variation: Evidence from complex predicates and complex word-formation. Language 77.2:324-342.

Snyder, William. 2012. Parameter theory and motion predicates. In Telicity, Change, and State: A Cross-Categorial View of Event Structure, ed. Violeta Demonte and Louise McNally, 279-299. Oxford: Oxford University Press. 
Son, Minjeong, and Peter Svenonius. 2008. Microparameters of cross-linguistic variation: Directed motion and resultatives. In Proceedings of WCCFL 27, ed. Natasha Abner and Jason Bishop, 388-396. Somerville, MA: Cascadilla Press.

von Stechow, Arnim. 1984. Comparing semantic theories of comparison. Journal of Semantics 3:1-77.

von Stechow, Arnim. 1995. Lexical decomposition in syntax. In Lexical Knowledge in the Organisation of Language, ed. Urs Egli, Peter E. Pause, Christoph Schwarze, Arnim von Stechow and Götz Wienold, 81-177. Amsterdam: John Benjamins.

von Stechow, Arnim. 1996. The different readings of wieder 'again': A structural account. Journal of Semantics 13:87-138.

von Stechow, Arnim. 2003. How are results represented? Remarks on Jäger and Blutner's anti-decomposition. In Modifying Adjuncts, ed. Ewald Lang, Claudia Maienborn and Catherine Fabricius-Hansen, 417-451. Berlin: de Gruyter.

Talmy, Leonard. 1985. Lexicalization patterns: Semantic structure in lexical forms. In Language Typology and Syntactic Descriptions III: Grammatical Categories and the Lexicon, ed. Timothy Shopen, 57-149. Cambridge: Cambridge University Press.

Tenny, Carol. 1987. Grammaticalizing Aspect and Affectedness. Ph.D. dissertation, MIT.

Tenny, Carol. 1994. Aspectual Roles and the Syntax-Semantics Interface. Dordrecht: Kluwer.

Traxler, Matthew J., Brian McElree, Rihana S. Williams and Martin J. Pickering. 2005. Context effects in coercion: Evidence from eye movement. Journal of Memory and Language 53:1-25.

Vendler, Zeno. 1957. Verbs and times. Philosophical Review 56:143-160.

Verkuyl, Henk. 1972. On the Compositional Nature of the Aspects. Dordrecht: Foundations of Language Supplement Series 15.

Verkuyl, Henk. 1993. A Theory of Aspectuality: The Interaction between Temporal and Atemporal Structure. Cambridge: Cambridge University Press.

Verkuyl Henk. 2000. Events as dividuals: Aspectual composition and event semantics. In Speaking of Events, ed. James Higginbotham, Fabrizio Pianesi, and Achille C. Varzi, 169-206. Oxford: Oxford University Press.

Zubizarreta, María Luisa, and Eunjeong Oh. 2007. On the Syntactic Composition of Manner and Motion. Cambridge, MA: MIT Press.

Zucchi, Sandro, and Michael White. 2001. Twigs, sequences and the temporal constitution of predicates. Linguistics and Philosophy 24:223-270.

Zwarts, Joost. 2005. Prepositional aspect and the algebra of paths. Linguistics and Philosophy 28.6:739-779.

Zwarts, Joost. 2006. Event shape: Paths in the semantics of verbs. Ms. Radboud University Nijmegen. 